We successfully condensed ETAT/ETAT + training to two courses of shorter duration. 'Essential ETAT' was well received by participants, and a significant improvement in post-course test scores was achieved. Further evaluation at 6 months post course is required to indicate whether knowledge is retained and changes clinical practise.

\section{G119 RECALL (RAPID EVALUATION OF CARDIO-RESPIRATORY ARRESTS WITH LESSONS FOR LEARNING): DEVELOPING A TOOL TO LEARN FROM PAEDIATRIC ARRESTS}

doi:10.1136/archdischild-2013-304107.131

1J Runnacles, ${ }^{2}$ S Chapman, ${ }^{2 P}$ Lachman. 'Department of Paediatrics, Kingston Hospital NHS Trust, Kingston-upon-Thames, UK; ${ }^{2}$ Quality, Safety and Transformation Team, Great Ormond Street Hospital for Children NHS Foundation Trust, London, UK

Aim Our Trust, a tertiary centre, aims to eliminate predictable cardio-respiratory arrests (CRA) outside of intensive care by the end of 2013. Although CRA in hospitalised children is rare, the majority are preventable (Tibballs et al 2005). Local incident reports highlighted areas of concern such as poor documentation and incomplete monitoring. Review processes are lengthy and focus on errors rather than areas for improvement. The aim was to develop a new approach to rapidly review all CRA's and share lessons with the relevant teams.

Method Experienced clinicians, safety experts and risk managers used a Plan-Do-Study-Act (PDSA) approach to develop RECALL:

PDSA cycles:

detailed study of recent CRA's by team to identify key areas to structure review tool

tested key areas for completeness, ease of use and relevance

key areas refined and tested again

categories identified for review: Assessment, Escalation, Clinical reviews, Interventions

tested proforma of questions to guide quick but systematic analysis of medical/nursing notes

Using care-bundle approach, five 'must do's' identified for each category
A traffic-light approach was applied to each category to communicate findings: Green (no areas for improvement), Amber (areas for improvement identified but unlikely to have prevented CRA) or Red (areas for improvement identified which may have prevented CRA). The RECALL tool was then tested prospectively over 8 weeks.

Results RECALL is now used to review all CRA at weekly meetings, each case taking 30minutes. Lessons for learning are disseminated weekly to the medical director, safety team and local safety leads (discussed at monthly board meetings). Changes are implemented locally with trustwide learning incorporated into improvement goals. The project has moved towards local team review with dissemination trustwide. Early results are promising with a reduced number of CRA (fig 1) and increased staff engagement.

Conclusion RECALL has facilitated a culture of learning so clinical teams understand how to improve recognition/escalation of seriously ill children. Common themes include completeness of observations and timeliness of interventions. A simple rapid assessment tool can provide timely and useful data that can be used to drive improvement.

\section{G120 KNOWLEDGE AND ATTITUDES; ESSENTIAL INGREDIENTS FOR DEVELOPING CO PRODUCED TAILORED INTERVENTIONS FOR ASTHMA MANAGEMENT (MIA) IN SOUTH ASIAN AND WHITE BRITISH CHILDREN}

doi:10.1136/archdischild-2013-304107.132

${ }^{2} \mathrm{D}$ Bird, ${ }^{3} \mathrm{~N}$ Hudson, ${ }^{3} \mathrm{~L}$ Culley, ${ }^{4} \mathrm{E}$ Angell, ${ }^{1} \mathrm{M}$ Lakhanpaul. ${ }^{1}$ General and Adolescent Paediatrics Unit, UCL Institute of Child Health, London, UK; ${ }^{2}$ Dept of Medical and Social Care Education, University of Leicester, Leicester, UK; ${ }^{3}$ School of Applied Social Sciences, De Montfort University, Leicester, UK; ${ }^{4}$ Department of Health Sciences, University of Leicester, Leicester, UK

Childhood asthma is a chronic illness affecting quality of life and leading to higher mortality in the UK than other countries. In the UK, prescription rates for relievers and preventers are lower for South Asian (SA) children. SA children are more likely to suffer uncontrolled symptoms and to be admitted to hospital with acute exacerbations compared to White British (WB) children. The MIA study aimed to

\begin{tabular}{|c|c|c|c|}
\hline & 1 & 3 & 5 \\
\hline 1. Approach & Confrontational, judgmental approach & $\begin{array}{c}\text { Attempts to establish rapport with the learner(s) } \\
\text { but is either over- critical or too informal in } \\
\text { manner }\end{array}$ & $\begin{array}{c}\text { Establishes and maintains rapport throughout; uses a } \\
\text { non- threatening but honest approach to create a } \\
\text { psychologically safe environment }\end{array}$ \\
\hline $\begin{array}{l}\text { 2. Establishes learning } \\
\text { environment }\end{array}$ & $\begin{array}{c}\text { Unclear expectations of the learner(s); inadequate } \\
\text { learning environment }\end{array}$ & $\begin{array}{c}\text { Explains purpose of the debriefing or learning } \\
\text { session but does not clarify learner(s) } \\
\text { expectations }\end{array}$ & $\begin{array}{l}\text { Explains purpose of debrief; clarifies objectives and } \\
\text { learner expectations from the beginning }\end{array}$ \\
\hline 3. Engagement of Learners & $\begin{array}{c}\text { Purely didactic; facilitator doing all of the talking } \\
\text { with no learner engagement; does not involve } \\
\text { passive learner(s) }\end{array}$ & $\begin{array}{c}\text { Learner(s) participates in the discussion but } \\
\text { through closed questions; facilitator does not } \\
\text { actively invite input from more passive learner(s) }\end{array}$ & $\begin{array}{c}\text { Encourages participation of learner(s) through } \\
\text { open-ended questions; invites learner(s) to actively } \\
\text { contribute to discussion }\end{array}$ \\
\hline 4. Reaction & $\begin{array}{l}\text { No acknowledgment of learner(s)' reactions, or } \\
\text { emotional impact of the experience }\end{array}$ & $\begin{array}{l}\text { Asks the learner(s) about their feelings but does } \\
\text { not fully explore their reaction to the experience }\end{array}$ & $\begin{array}{c}\text { Fully explores learner(s)'s reaction to the experience, } \\
\text { appropriately managing any learner(s) who is } \\
\text { confused or unhappy }\end{array}$ \\
\hline 5. Descriptive Reflection & $\begin{array}{l}\text { No opportunity for self- reflection; learner(s) not } \\
\text { asked to describe what actually happened in the } \\
\text { scenario }\end{array}$ & $\begin{array}{c}\text { Some description of events by facilitator, but with } \\
\text { little self-reflection by learner(s) }\end{array}$ & $\begin{array}{c}\text { Encourages learner(s) to self-reflect upon experience } \\
\text { using a step by step approach }\end{array}$ \\
\hline 6. Analysis & $\begin{array}{l}\text { Reasons and consequences of actions are not } \\
\text { explored with the learner(s) }\end{array}$ & $\begin{array}{c}\text { Some exploration of reasons and consequences of } \\
\text { actions by facilitator but not learner(s) }\end{array}$ & $\begin{array}{l}\text { Helps learner(s) to explore reasons and conse- } \\
\text { quences of actions, identifying specific examples; } \\
\text { relates it back to previous experience to offer } \\
\text { explanations }\end{array}$ \\
\hline 7. Diagnosis & $\begin{array}{c}\text { No feedback on clinical or teamwork skills; does } \\
\text { not identify performance gaps or provide positive } \\
\text { reinforcement }\end{array}$ & $\begin{array}{l}\text { Feedback provided only on clinical (technical) } \\
\text { skills; focuses on errors only; does not target } \\
\text { behaviours that can be changed. }\end{array}$ & $\begin{array}{c}\text { Provides feedback on clinical (technical) and } \\
\text { teamwork skills; identifies positive behaviours in } \\
\text { addition to performance gaps, targets changeable } \\
\text { behaviours }\end{array}$ \\
\hline 8. Application & $\begin{array}{l}\text { No opportunity for learner(s) to identify } \\
\text { strategies for future improvement or to } \\
\text { consolidate key learning points }\end{array}$ & $\begin{array}{c}\text { Some discussion of learning points and strategies } \\
\text { for improvement but lack of application of this } \\
\text { knowledge to future practice }\end{array}$ & $\begin{array}{c}\text { Reinforces key learning points identified by learner(s) } \\
\text { and highlights how strategies for improvement could } \\
\text { be applied to future clinical practice }\end{array}$ \\
\hline
\end{tabular}

Abstract G119 Figure 1 Objective Structured Assessment of Debriefing (OSAD) in Paediatrics 
co-produce a tailored intervention framework for childhood asthma management by exploring the knowledge and attitudes towards asthma amongst WB and SA parents, carers and children.

Methods Semi-structured interviews with a purposive sample of 44 children aged 5-12yrs (33 SA, $14 \mathrm{WB}$ ) and 65 parents/carers (49 $\mathrm{SA}, 16 \mathrm{WB}$ ) were used to explore barriers and facilitators to asthma management. A comparative thematic analysis was conducted.

Results WB families were more likely to have pre-existing knowledge of asthma than SA families; previous knowledge of asthma strongly influenced how families managed childhood asthma in both communities. In a minority of SA families, 'fear of the unknown' prevented families from investigating asthma further. Beliefs regarding the causes and nature of asthma were similar in both groups, however whilst 33\% of SA families attributed asthma to either God's will or Karma, no WB families did so.

All communities reported that advice was often given by extended family members but this was more prominent in SA families, especially in relation to complementary asthma management strategies.

SA and WB families both reported a lack of information-giving by health care professionals in relation to asthma.

Conclusions Pre-existing knowledge and attitudes surrounding asthma differ between SA and WB parents and directly impact on management. Intervention Co-production is increasing in use and popularity. The MIA project supports the co-production model by highlighting the importance of identifying attitudes and beliefs towards asthma from different ethnic groups so that interventions can be tailored to address their fears and concerns more effectively. Disclaimer This project was funded by the National Institute for Health Research HS\&DR programme (ref 09/2001/19). The views and opinions expressed therein are those of the authors and do not necessarily reflect those of the HS\&DR programme, NIHR, NHS or the Department of Health.

\section{G121 ARE WE OVERINVESTIGATING HYPOGLYCAEMIA IN CHILDREN PRESENTING WITH GASTROENTERITIS IN A DISTRICT GENERAL HOSPITAL SETTING?}

doi:10.1136/archdischild-2013-304107.133
${ }^{1} \mathrm{~S}$ Austin, ${ }^{2} \mathrm{~S}$ Birch, ${ }^{2} \mathrm{~J}$ Walker, ${ }^{2} \mathrm{~N}$ Wickramsuriya, ${ }^{1} \mathrm{~V}$ Walker, ${ }^{3} \mathrm{~L}$ Wainwright, ${ }^{2} \mathrm{~S}$ Gray. 'Paediatrics, University Hospital Southampton, Southampton, UK; ${ }^{2}$ Paediatrics, Queen Alexandra Hospital, Portsmouth, UK; ${ }^{3}$ Biochemical Sciences, Queen Alexandra Hospital, Portsmouth, UK

Aims To develop a safe but less invasive approach to the investigation and management of hypoglycaemia in infants and children.

Methods 2010 We performed an audit of all hypoglycaemia screens undertaken between 1st February-12th May in a large district general hospital using retrospective case-note analysis.

Using these results we conducted a consultation exercise involving local consultants, biochemists and a tertiary metabolic specialist to develop a simple screening pathway that was also in line with the National Metabolic Biochemistry Network (NMBN) guidelines for investigation and management of hypoglycaemia. The pathway emphasises that symptomatic hypoglycaemia is a clinical emergency and permanent brain damage is a risk if treatment is delayed.

Table 1: 1st February 2011: The screening pathway was introduced into clinical practise

Table 2: 2011 \& 2012: Re-audit of clinical practise in both years for the same time period (1st February- 12th May)

Results In 2010, 22 hypoglycaemia screens were performed, all of which were normal, except for a recurrent finding of mildly elevated 3 hydroxy-butyrylcarnitine (as would be expected during fasting). 19 sets of case-notes were obtained. These showed 18/19 children had gastroenteritis, $17 / 19$ had no significant past medical history and 16/19 were admitted.

In 2011 and 2012 there was a substantial reduction in the number of screens performed in infants and children (10 in 2011; 7 in 2012). No significant abnormalities have been identified. The admission and follow up data for 2011 \& 2012 is currently being analysed.

Total numbers of infants and children referred to hospital, and the proportion of children diagnosed with gastroenteritis were similar in all three years.

Conclusions Analysis of practise in 2010 highlighted a population of previously well children who presented with symptoms of gastroenteritis and were incidentally found to have hypoglycaemia and were therefore investigated accordingly.

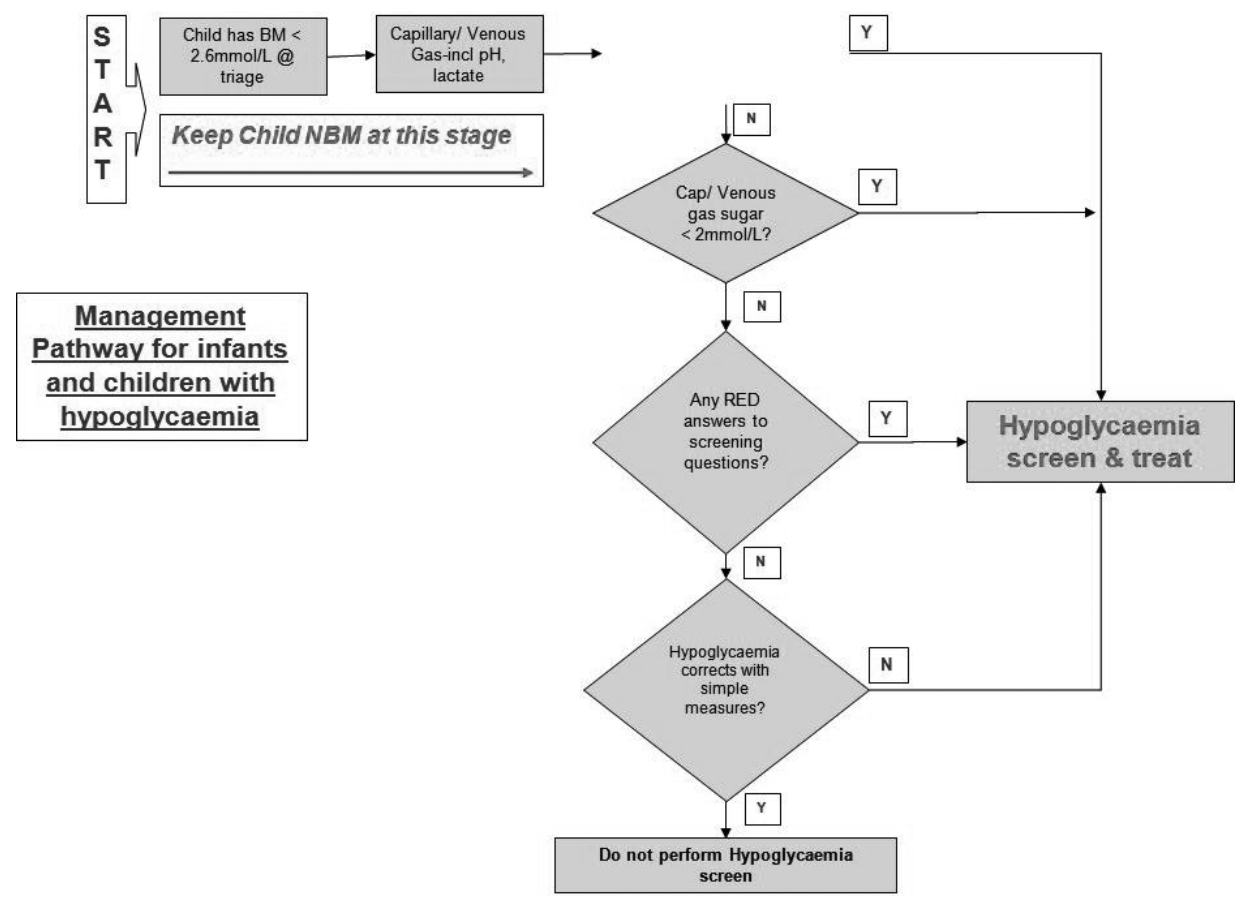

